\title{
Comparing impacts of metal contamination on macroinvertebrate and fish assemblages in a northern Japanese river
}

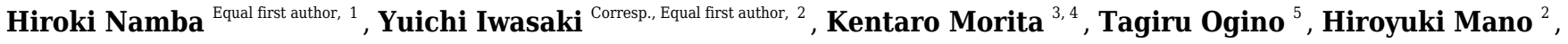 \\ Naohide Shinohara ${ }^{2}$, Tetsuo Yasutaka ${ }^{6}$, Hiroyuki Matsuda ${ }^{1}$, Masashi Kamo ${ }^{2}$ \\ ${ }^{1}$ Graduate School of Environment and Information Sciences, Yokohama National University, Yokohama, Kanagawa, Japan \\ 2 Research Institute of Science for Safety and Sustainability, National Institute of Advanced Industrial Science and Technology, Tsukuba, Ibaraki, Japan \\ 3 Japan Fisheries Research and Education Agency, Sapporo, Hokkaido, Japan \\ 4 Field Science Center for Northern Biosphere, Hokkaido University, Horokanai, Hokkaido, Japan \\ 5 Geological Survey of Hokkaido, Hokkaido Research Organization, Sapporo, Hokkaido, Japan \\ 6 Research Institute for Geo-Resources and Environment, National Institute of Advanced Industrial Science and Technology, Tsukuba, Ibaraki, Japan \\ Corresponding Author: Yuichi Iwasaki \\ Email address: yuichiwsk@gmail.com
}

Researchers have long assessed the ecological impacts of metals in running waters, but few such studies investigated multiple biological groups. Our goals in this study were to assess the ecological impacts of metal contamination on macroinvertebrates and fishes in a northern Japanese river receiving treated mine discharge and to evaluate whether there was any difference between the metrics based on macroinvertebrates and those based on fishes in assessing these impacts. Macroinvertebrate communities and fish populations were little affected at the downstream contaminated sites where concentrations of $\mathrm{Cu}, \mathrm{Zn}$, $\mathrm{Pb}$, and $\mathrm{Cd}$ were 0.1-1.5 times higher than water-quality criteria established by the U.S. Environmental Protection Agency. We detected a significant reduction in a few macroinvertebrate metrics such as mayfly richness and the abundance of heptageniid mayflies at the two most upstream contaminated sites with metal concentrations 0.8-3.7 times higher than the water-quality criteria. There were, however, no remarkable effects on the abundance or condition factor of the four dominant fishes, including masu salmon (Oncorhynchus masou). These results suggest that the richness and abundance of macroinvertebrates are more sensitive to metal contamination than abundance and condition factor of fishes in the studied river. Because the sensitivity to metal contamination can depend on the biological metrics used, and fish-based metrics in this study were limited, it would be valuable to accumulate empirical evidence for ecological indicators sensitive to metal contamination within and among biological groups to help in choosing which groups to survey for general environmental impact assessments in metalcontaminated rivers. 
1 Comparing impacts of metal contamination on macroinvertebrate and fish assemblages in

2 a northern Japanese river

3

4 Hiroki Namba ${ }^{1}$, Yuichi Iwasaki ${ }^{2}$, Kentaro Morita ${ }^{3,4}$, Tagiru Ogino ${ }^{5}$, Hiroyuki Mano ${ }^{2}$, Naohide

5 Shinohara $^{2}$, Tetsuo Yasutaka ${ }^{6}$, Hiroyuki Matsuda ${ }^{1}$, Masashi Kamo ${ }^{2}$

6

$7{ }^{1}$ Graduate School of Environment and Information Sciences, Yokohama National University,

8 Yokohama, Kanagawa, Japan

$9 \quad{ }^{2}$ Research Institute of Science for Safety and Sustainability, National Institute of Advanced

10 Industrial Science and Technology, Tsukuba, Ibaraki, Japan

11 Japan Fisheries Research and Education Agency, Sapporo Hokkaido, Japan

$12{ }^{4}$ Field Science Center for Northern Biosphere, Hokkaido University, Horokanai, Hokkaido,

13 Japan

$14{ }^{5}$ Geological Survey of Hokkaido, Hokkaido Research Organization, Sapporo, Hokkaido, Japan

$15{ }^{6}$ Research Institute for Geo-Resources and Environment, National Institute of Advanced

16 Industrial Science and Technology, Tsukuba, Ibaraki, Japan

18 Corresponding Author:

19 Yuichi Iwasaki

20 16-1 Onogawa, Tsukuba, Ibaraki 305-8569, Japan

21 Email address: yuichiwsk@gmail.com 


\section{Abstract}

Researchers have long assessed the ecological impacts of metals in running waters, but few such studies investigated multiple biological groups. Our goals in this study were to assess the ecological impacts of metal contamination on macroinvertebrates and fishes in a northern Japanese river receiving treated mine discharge and to evaluate whether there was any difference between the metrics based on macroinvertebrates and those based on fishes in assessing these impacts. Macroinvertebrate communities and fish populations were little affected at the downstream contaminated sites where concentrations of $\mathrm{Cu}, \mathrm{Zn}, \mathrm{Pb}$, and $\mathrm{Cd}$ were $0.1-1.5$ times higher than water-quality criteria established by the U.S. Environmental Protection Agency. We detected a significant reduction in a few macroinvertebrate metrics such as mayfly richness and the abundance of heptageniid mayflies at the two most upstream contaminated sites with metal concentrations $0.8-3.7$ times higher than the water-quality criteria. There were, however, no remarkable effects on the abundance or condition factor of the four dominant fishes, including masu salmon (Oncorhynchus masou). These results suggest that the richness and abundance of macroinvertebrates are more sensitive to metal contamination than abundance and condition factor of fishes in the studied river. Because the sensitivity to metal contamination can depend on the biological metrics used, and fish-based metrics in this study were limited, it would be valuable to accumulate empirical evidence for ecological indicators sensitive to metal contamination within and among biological groups to help in choosing which groups to survey for general environmental impact assessments in metal-contaminated rivers.

Keywords: Aquatic insects, fish, trace metals, abandoned mines, legacy mines, cross taxon congruence, environmental assessment, ecological risk assessment 


\section{Introduction}

The impact of trace metals on aquatic ecosystems is an important issue in many regions of the world (Nriagu \& Pacyna, 1988; Iwasaki \& Ormerod, 2012). Laboratory toxicity tests of surrogate species are routinely used to assess the potential effects of metals on aquatic organisms and to provide a first step in inferring the effects on ecosystems. Responses of surrogate species in the laboratory, however, are not necessarily a good indicator for predicting responses of natural populations and communities because of, for example, the short test durations and failures to consider sensitive life stages, dietary exposure, and/or interspecies interactions (Kimball \& Levin, 1985; Niederlehner et al., 1990; Hickey \& Clements, 1998; Clements, Cadmus \& Brinkman, 2013; Iwasaki, Schmidt \& Clements, 2018). Thus, biological assessments of natural aquatic populations and communities that likely reflect time-integrated effects can provide useful information for evaluating ecological impairments in actual environments (Barbour et al., 1999).

In conducting the biological assessments in natural environments, the first question to answer is which aquatic organisms are to be investigated. For example, benthic macroinvertebrates have a wide range of sensitivities to contamination by metals (Iwasaki, Schmidt \& Clements, 2018). Also, macroinvertebrates have been the most frequently used in assessing the ecological impacts of metals in streams and rivers (Namba et al., 2020). Studies have indicated, however, that in aquatic ecosystems there are generally low correlations between changes in different biological groups (Heino, 2010; de Morais et al., 2018; Namba et al., 2020). Despite this observation, a surprisingly limited number of studies published in peer-reviewed journals have investigated multiple biological groups in metal-contaminated rivers (Freund \& Petty, 2007; Namba et al., 2020). Therefore, to provide a more comprehensive assessment for overall ecosystem protection, 
67 it is important to investigate responses of not only macroinvertebrates but also other biological

68

69 groups such as fishes in metal-contaminated rivers and to accumulate such case studies to better understand the ecological impacts of metal contamination on different biological groups.

The closed Motokura mine is located in the upstream area of the Tokushibetsu River in northern Japan (Figure 1). The mine mainly produced $\mathrm{Cu}, \mathrm{Pb}$, and $\mathrm{Zn}$. In 1962, there were mass mortalities of Pacific salmon (Oncorhynchus spp.) in the river and Takayasu et al. (1964) concluded that mine drainage discharged into the river was likely a major cause. Even after the mine closure in 1967 , treated mine drainage has been perennially discharged into a small tributary of the contaminated river (Figure 1), which provides a unique opportunity to investigate any ecological consequences of the long-term exposure. A bioassessment in 2017 using only macroinvertebrates showed that the abundance and richness of macroinvertebrates were little affected at downstream sites in the Tokushibetsu River (Iwasaki et al., 2020b). Given that recreational fishing for salmonids is popular in this region (Hokkaido Island, Japan; Miyakoshi et al., 2009) and hatchery-reared masu salmon are released into the river system, it is important to evaluate the effects of mine drainage on not only macroinvertebrates as food resources for fish, but also on fish communities. However, no recent studies have evaluated the effects of mine discharge on fish in the river (but see Takayasu et al., 1964). We thus aimed to assess whether there are ecological impacts in the contaminated river by investigating macroinvertebrates and fishes. By doing so, we also evaluated whether there were any differences between metrics based on macroinvertebrates and those using fishes in detecting the effects of metal contamination. 87

\section{Materials \& Methods}

Study site 
90 Field sampling of macroinvertebrates, fishes, and physicochemical characteristics was performed

91 at nine sites in the Tokushibetsu River system on Hokkaido Island, northern Japan (Figure 1)

92 from 26 to 28 June 2018. Except for the fish survey, the methods adopted were described for a

93 previous study in June 2017 by Iwasaki et al. (2020b). The basin area of the Tokushibetsu River

94 system is approximately $300 \mathrm{~km}^{2}$, and the predominant land uses are forest $(88 \%)$ and

95 agriculture (<10\%; mainly meadow), with little urban use $(<1 \%)$ according to Iwasaki et al.

96 (2020a). The geology of the studied catchment is characterized mainly by igneous rocks,

97 followed by sedimentary rocks (Geological Survey of Japan, 2015).

98 Five of the nine sites (sites S1a-S4) were in the Ofuntarumanai River, a metal-contaminated

99

100

101

102

103

104

105

106

107

108

109

110

111 stream receiving treated mine discharge, and four reference sites (R1-R4) were in the main

stream of the Tokushibetsu River. The reference sites, with similar physicochemical

characteristics other than metal contamination (e.g., channel width), were established at similar

elevations as the contaminated sites to avoid problems caused by natural longitudinal changes in

community structure (Clements, 1994; Tokeshi, 2009; Iwasaki et al., 2012; Morita, Sahashi \&

Tsuboi, 2016). Study sites with the same numbers had similar elevation levels, for example S1 (a

and b) and R1 (Table 1). These study sites were on third- or fourth-order rivers. Sites S1a and

$\mathrm{S} 1 \mathrm{~b}$ were upstream and downstream of the inflow of treated mine discharge, respectively (Figure

1). Because the treated discharge was not the sole source of metal contamination in the

Ofuntarumanai River (Iwasaki et al., 2020b) and there was a contaminated tributary upstream of

S1a (Takayasu et al., 1964), we regarded S1a as a contaminated site (see below for more details).

Permits for field sampling in the river were obtained from the local municipal office and

Hokkaido government. 
112

113

Similar field sampling was performed at the same nine sites in the Tokushibetsu River system on 26 and 27 September 2018. This field sampling was carried out by the Japanese Ministry of Economy, Trade and Industry, and the results are publicly available (see Supplemental materials for more details). The field sampling method for benthic macroinvertebrates in this survey was different from that in the present study and no replicates were taken at seven of the nine sites; thus, it was difficult to simultaneously analyze the field data collected in both June and September 2018. Instead, we note the results of the additional field study in the Discussion section to evaluate our findings based on the field sampling conducted in June 2018.

\section{Water-quality parameters}

During field sampling, three water samples $(50 \mathrm{ml})$ were filtered from each study site for dissolved metals analysis $(0.45 \mu \mathrm{m}$ pore-size $)$ and refrigerated in the field. Ultrapure nitric acid was added to those water samples on the day of sampling so that the $\mathrm{pH}$ was less than 2 .

Concentrations of dissolved $\mathrm{Cu}, \mathrm{Zn}, \mathrm{Cd}$, and $\mathrm{Pb}$ were measured by using an inductively coupled plasma mass spectrometer (Element XR, Thermo Fisher Scientific, Tokyo, Japan) according to method 200.8 of the U.S. Environmental Protection Agency (U.S. EPA, 1994). The limits of quantification were $0.001 \mu \mathrm{g} / \mathrm{L}$ for $\mathrm{Cu}, 0.06 \mu \mathrm{g} / \mathrm{L}$ for $\mathrm{Zn}$, and $0.005 \mu \mathrm{g} / \mathrm{L}$ for both $\mathrm{Cd}$ and $\mathrm{Pb}$.

Water temperature, dissolved oxygen, $\mathrm{pH}$, and electrical conductivity were measured by using multi-parameter portable meters (Multi 3630IDS, Xylem Analytics Germany, Weilheim, Germany). Filtered water samples were also collected for measuring concentrations of dissolved organic carbon (DOC) and major ions $\left(\mathrm{Na}^{+}, \mathrm{K}^{+}, \mathrm{Ca}^{2+}, \mathrm{Mg}^{2+}, \mathrm{Cl}^{-}\right.$, and $\left.\mathrm{SO}_{4}{ }^{2-}\right)$. DOC was measured with a total organic carbon analyzer (TOC-L CPH, Shimadzu, Kyoto, Japan). Concentrations of 
135 major ions were measured with an ion chromatograph (Dionex ICS-1100/2100, Thermo Fisher

136 Scientific). We calculated water hardness as $2.497 \times\left[\mathrm{Ca}^{2+}\right]+4.118 \times\left[\mathrm{Mg}^{2+}\right]$.

137

138

139

140

141

142

143

144

145

146

147

148

149

150

151

152

153

154

155

156

157

As an index of contamination by multiple metals, we calculated the cumulative criterion unit (CCU; Clements et al., 2000) as the sum of the ratios of measured concentrations of four metals to the U.S. EPA hardness-adjusted water-quality criteria for aquatic life (WQC; U.S. EPA, 2002) because the water quality standards for aquatic life are available only for $\mathrm{Zn}$ in Japan:

where $m_{i}$ is the concentration of dissolved metal $i$ and $c_{i}$ is the corresponding WQC. Hardnessadjusted WQC for $\mathrm{Cu}, \mathrm{Zn}, \mathrm{Cd}$, and $\mathrm{Pb}$ were calculated at a water hardness of $10 \mathrm{mg} / \mathrm{L}$ based on the observed range of water hardness in this study (Table 2) and a previous study of the same river (Iwasaki et al., 2020b). Note that, because the hardness of $10 \mathrm{mg} / \mathrm{L}$ is below the lower end of the hardness range of toxicity data used in the WQC development (20 mg/L; U.S. EPA, 2002), caution is required for the interpretation of the calculated CCU values. Also, we did not consider water quality variables other than water hardness (e.g., $\mathrm{pH}$ and DOC) in this calculation (Iwasaki et al., 2020b). This is because these variables varied little among study sites (Table 2), and U.S. EPA WQC based on biotic ligand models that can consider the influence of water chemistry on metal toxicity were available only for Cu (U.S. EPA, 2007).

\section{Physical parameters}

Average channel width (surface-water width measured at run) and riffle width were measured at each study site. Riffle width was averaged if benthic macroinvertebrates were collected at 
158 multiple riffles within individual sites. The catchment area of each site was quantified using a

159 digital elevation model (50-m grid; Geographical Survey Institute of Japan,

160 www.gsi.go.jp/ENGLISH/index.html) and a geographic information system (ArcGIS 10.2 for

161 Desktop, Esri Japan, Tokyo, Japan). Maximum water velocity and depth were evaluated on the

162 basis of measurements at multiple places in riffles from which macroinvertebrates were collected

163 at each study site. Current velocity was measured at $60 \%$ of water depth using an

164 electromagnetic velocity meter (VR-301; Kenek, Tokyo, Japan).

165

166

167

168

169

170

171

172

173

174

175

176

177

178

179

180

\section{Macroinvertebrates}

At cobble-dominated riffles at each site, we collected macroinvertebrates from five randomly chosen stones (maximum diameter, 14-27 cm) using a Surber net (mesh size, $0.355 \mathrm{~mm}$ ).

Samples were preserved in the field in $99.5 \%$ ethanol and washed through a $0.5-\mathrm{mm}$ sieve in the laboratory. Macroinvertebrates remaining on the sieve were preserved in $70 \%$ ethanol and identified generally to genus or species level. For each stone from which macroinvertebrates were collected, water depth and current velocity (at 60\% depth) were measured above its upper surface before collecting macroinvertebrates. The relative surface area of each stone was estimated as the product of its maximum diameter and maximum boundary length. Although the mesh size of the sieve used in this study $(0.5 \mathrm{~mm})$ is commonly adopted in nationwide samplings of benthic macroinvertebrates in Japan, the smaller mesh size (i.e., $0.35 \mathrm{~mm}$ ) can collect smaller individuals, which are more sensitive to metal contamination than larger ones (Cadmus et al., 2020). However, because our sampling was performed in late spring, when most insect individuals are expected to be at late larval stages and larger than $0.5 \mathrm{~mm}$, the use of the smaller mesh size should not have materially changed our results. 
We analyzed eight community metrics for abundance (the number of individuals per stone) and richness (the number of taxa per stone): total abundance, total taxon richness, and the abundance and richness of three major aquatic insect orders in the benthic samples collected: Ephemeroptera (mayflies), Trichoptera (caddisflies), and Diptera (true flies). We also determined the abundance of the dominant families (i.e., Ephemerellidae, Baetidae, Heptageniidae, Hydropsychidae, Chironomidae, and Simuliidae) of the three major aquatic groups, which were defined as those families that accounted for more than $5 \%$ of the total abundance at each sampled stone and that were collected at more than $30 \%$ of the sampled stones (i.e., more than 14 stones of a total of 45 stones collected). For all macroinvertebrate metrics, the means and standard errors (as indicators for the uncertainty in site mean) of five stones at each site were calculated and used for further analyses. Macroinvertebrate abundances were $\log _{10}$-transformed $(x+1)$ before calculation of the site means to satisfy the assumptions of further analyses.

\section{Fishes}

At each site, we established five fish-sampling areas of approximately $5 \mathrm{~m} \times 10 \mathrm{~m}$ to cover all of the habitats available (e.g., run, riffle, pool, and backwater) as much as possible. The distance between sampling areas was set to be $>20 \mathrm{~m}$. Fishes were collected from the downstream to the upstream end of each sampling area by using a backpack electrofishing unit (200-300 VDC; LR20B, Smith-Root, Inc., Vancouver, WA, USA) and by throwing a cast-net. After one pass electrofishing, we used a cast-net four or five times within each sampling area to catch fishes in places where the pool was too deep for electrofishing to work. For the fish collection, we did not use block nets because it was impractical to effectively put them in place without disturbance. However, by expending a certain amount of effort, our sampling methods should be acceptable 
204 for comparing the abundances of fish communities. The captured fishes were anesthetized with 205 phenoxyethanol and identified to species level if possible. The fork length was measured to the

206

207

208

209

210

211

212

213

214

215

216

217

218

219

220

221

222

223

224

225 226 nearest $1 \mathrm{~mm}$ and body weight was measured to the nearest $0.1 \mathrm{~g}$ onsite.

A total of five fish species were collected: Oncorhynchus masou (masu salmon; Salmonidae), Salvelinus leucomaenis (white-spotted char; Salmonidae), Barbatula oreas (stone loach; Nemacheilidae), Lethenteron spp. (lamprey; Petromyzontidae), and Tribolodon spp. (Cyprinidae). We excluded Tribolodon spp. from the analyses because of their very limited abundance in our samples (only two individuals collected at R4) and determined the abundance (the number of individuals per sampling area) and condition factor of the other four species. The abundances of fishes were $\log _{10}$-transformed $(x+1)$, and the means and standard errors of the five replicate samplings at each site were used for later analyses. Also, the condition factor (CF) was calculated as an indicator representing the health status of individual fish by using the following equation:

8

$$
\mathrm{CF}=\text { body weight }(\mathrm{g}) /[\text { fork length }(\mathrm{cm})]^{3} \times 1000
$$

The condition factor is relatively easy to measure in the field and is a sensitive measure for detecting population-level consequences of metal contamination (Munkittrick \& Dixon, 1989a; Environment and Climate Change Canada, 2015). Condition factor data were pooled at individual sites and used in later analyses.

Approximately 128,000 individual hatchery-reared masu salmon fry (O. masou; mean fork length: $5.6 \mathrm{~cm}$ ) were released at a location between $\mathrm{S} 1 \mathrm{~b}$ and $\mathrm{S} 2$ on the contaminated river on 6 June 2018. Masu salmon were also released at three other locations including a tributary between 
227 R1 and R2 in the Tokushibetsu River basin in April and June 2018. All released fry had 228 thermally induced otolith marks (Volk, Schroder \& Grimm, 1999). To estimate the proportion of

229

230

231

232

233

234

235

236

237

238

239

240

241

242

243

244

245

246

247

248

249

wild (natural-origin) and hatchery fish at each site, we sampled and checked the otolith marks of 20-27 masu salmon captured from each site in the laboratory. We then tested whether the inclusion of hatchery fish affected the results of our analyses.

\section{Data analysis}

All statistical tests were performed using R version 3.6.1 (R Core Team, 2019). A significance level $(\alpha)$ of 0.05 was used. All the data used are available in the Supplementary File. In order to evaluate any effects at the five contaminated sites in the river receiving the mine discharge (i.e., S1a-S4), we first evaluated whether the site mean for each biological metric was within the $90 \%$ confidence interval for the four reference sites calculated on the basis of the standard deviation of the reference site means. We refer to the $90 \%$ confidence intervals as "reference ranges" that are assumed as likely observed ranges at reference sites. We then examined whether there were statistically significant differences in biological metrics between each contaminated site and the corresponding reference site with a similar elevation (R1 vs. S1a, R1 vs. S1b, R2 vs. S2, R3 vs. S3, R4 vs. S4) by using a multiple comparison test (the single-step $P$-value adjustment; Bretz, Hothorn \& Westfall, 2010) after analysis of variance.

We used the results of these two analyses to operationally interpret the findings in three ways. If the mean of a given biological metric at a contaminated site was lower or higher than the corresponding reference range and was significantly lower or higher than that of the corresponding reference site by the multiple comparison test, we report that as an "adverse 
250 effect". If either one of these two results was observed we report that as "some effect of concern"

251 and if neither was observed, we conclude that there was "no effect of concern."

252

253 Results

254 Physicochemical parameters

255 Concentrations of the four trace metals $(\mathrm{Cu}, \mathrm{Zn}, \mathrm{Cd}$, and $\mathrm{Pb})$ at the contaminated sites $(\mathrm{S} 1 \mathrm{a}-\mathrm{S} 4)$

256 were approximately 2 to 190 times higher than the concentrations at the corresponding reference

257 sites at similar elevations, except for the concentration of $\mathrm{Zn}(25 \mu \mathrm{g} / \mathrm{L})$ at reference site $\mathrm{R} 1$,

258 which was similar to the concentrations at S1a and S1b (Table 2). Concentrations of the metals

259 excluding $\mathrm{Cu}$ at many contaminated sites were higher than the values of the U.S. EPA hardness-

260 adjusted WQC for aquatic life, with higher concentrations and CCU values at the upstream sites.

261 As previously observed (Iwasaki et al., 2020b), there was little difference in metal concentrations

262 between the site just upstream (S1a) and just downstream (S1b) of the inflow of treated

263 discharge. This is most likely due to the high concentrations of metals in an upstream tributary

264 draining the mining area (Iwasaki et al., personal observations, 2019; this is beyond the scope of

265 the present study). CCU values were greater than 1 at all of the contaminated sites except for S4,

266 indicating potential ecological risks based solely on the concentrations of the trace metals

267 measured.

268 There were marginally lower values of $\mathrm{pH}, \mathrm{DOC}$, and water hardness at the metal-

269 contaminated sites compared with reference sites (Table 2), all of which generally increase the

270 bioavailability of metals (Adams et al., 2020). The estimated catchment areas of the metal-

271 contaminated sites were generally larger than those of the corresponding reference sites with 
272 similar elevations (particularly between S2 and R2, and S3 and R3; Table 1), but other physical

273 parameters were similar at those sites.

274

275 Macroinvertebrates and fishes

276 All eight community metrics for macroinvertebrates at S3 and S4 were within the reference

277 ranges and were not significantly different from those at the corresponding reference sites

278 (Figure 2), indicating that there were no effects of concern at those contaminated sites. On the

279

280

281

282

283

284

285

286

287

288

289

290

291

292

293

294 other hand, there were adverse effects or some effects of concern for several of the community metrics at the upstream contaminated sites (S1a, S1b, and S2). For example, the mayfly richness at S2 (46\% lower than at R2), the mayfly abundance at S1b (58\% lower than at R1), and the caddisfly abundance at $\mathrm{S} 1 \mathrm{~b}(83 \%$ lower that at $\mathrm{R} 1)$, were lower than the reference ranges and significantly lower than at the corresponding reference sites.

As with the metrics for the macroinvertebrate community, there were no effects of concern for the abundances of any of the six dominant macroinvertebrate families at S3 and S4 (Figure 3). Although the variations within individual sites (i.e., the $90 \%$ confidence intervals of site means) were relatively large, the abundances of heptageniid mayflies at S1a and S1b (68\% lower than R1) and the abundance of hydropsychid caddisflies at S1a (84\% lower than R1) were lower than the reference ranges and significantly lower than at the corresponding reference sites, indicating adverse effects. Furthermore, there were some effects of concern for the abundances of Simuliidae and Chironomidae at some of the upstream contaminated sites (S1a, S1b, and S2).

No adverse effects were detected for the abundances or condition factors of the four fish species sampled, except for the abundance of masu salmon at S3. Although there were some occasional effects of concern (e.g., the abundances of white-spotted char at S1a and S1b and $B$. 
295

296

297

298

299

300

301

302

303

304

305

306

307

308

309

310

311

312

313

314

315

316

317

oreas at S2-S4; Figure 4), the sites where significant differences were observed or the mean value was higher or lower than the reference range varied depending on species. Lamprey (Lethenteron spp.) were not collected at most of the contaminated sites (i.e., S1a-S3), but the numbers of lamprey collected were also limited at the reference sites (R2-R4; a total of 5-15 individuals per site) and their variations were relatively large (see Figure 4). An adverse effect was detected for the abundance of masu salmon at S3, whereas there were no effects of concern for this metric at the other contaminated sites. The estimated proportions of released hatchery masu salmon at three of the reference sites $(\mathrm{R} 1, \mathrm{R} 3, \mathrm{R} 4)$ and two of the contaminated sites (S1a, $\mathrm{S} 1 b$ ) were $0 \%$, whereas at R2, S2, S3, and S4 the proportions were $9 \%$ (2 of 23$), 48 \%$ (13 of 27 ), $5 \%$ ( 1 of 21 ), and $18 \%$ ( 4 of 22 ), respectively. We estimated the abundances of wild masu salmon at each site using these proportions and reran the two analyses. The reanalysis did not change the conclusions on the effects of mine contamination on the abundance of masu salmon at contaminated sites.

\section{Discussion}

Our results suggest that macroinvertebrate communities and fish populations at the two downstream sites in the contaminated river in northern Japan, with CCU values $<4$, were little affected by metal contamination. This is consistent with the results of a previous study in 2017 sampling benthic macroinvertebrates (see Iwasaki et al. (2020b) for the detailed discussion about the relationship between CCUs and effects on macroinvertebrate richness and abundance). Although we observed a significant decrease in the abundance of masu salmon at S3, this is unlikely due to metal contamination because no such decrease was observed at the contaminated sites farther upstream with higher metal concentrations (Figure 4). 
The concentration of dissolved $\mathrm{Zn}$ at the most upstream reference site (R1; Table 2) was

319 relatively high compared with other reference sites and the U.S. EPA WQC (the CCU value was

3202.1 at this site). The relative standard deviation for $\mathrm{Zn}$ based on three replicate water samples

321 was small (2\%) at R1. Although there were no measurements before the sampling campaign, the

$322 \mathrm{Zn}$ concentration at R1 was comparable to other reference sites in the sampling conducted in

323 September $2018(1.0 \mu \mathrm{g} / \mathrm{L}$; Table S1). It is impossible to determine the underlying reasons for

324 the relatively high $\mathrm{Zn}$ concentration at $\mathrm{R} 1$, but it is reasonable to regard $\mathrm{R} 1$ as a reference site

325 given that we detected no effects on macroinvertebrates and fishes at S3 and S4 with CCUs $<4$.

326 Furthermore, although our results on metal concentrations and CCUs were based on single-

327

328

329

330

331

332

333

334

335

336

337

338

339

340

occasion grab samples, the metal concentrations at the study sites were generally similar to those in the field studies performed in June 2017 (Iwasaki et al., 2020b) and September 2018 (Table

S1). Also, the mean concentrations ( \pm standard errors) of total Zn were $24( \pm 2)$ at S2 (five samples in May-October, 2017) and $10( \pm 2)$ at S4 (10 samples in May-February, 2017)

(Hokkaido Prefecture, 2018). As was also observed by Iwasaki et al. (2020b), these results provide modest support that our measurements during the field sampling can be regarded as approximate annual means of metal concentrations in the studied river.

At the two upstream sites (S1a and S1b) with CCU values of approximately 9, we detected adverse effects with some macroinvertebrate metrics, such as the mayfly abundance and the abundance of heptageniid mayflies. Similar results were obtained in the benthic macroinvertebrate sampling in September 2018 (Figures S1 and S2). Among the macroinvertebrate metrics, mayfly richness and abundance are relatively sensitive to changes in metal contamination levels (Carlisle \& Clements, 1999; Clements, Vieira \& Church, 2010) and heptageniid mayflies are also well known as one of the families most sensitive to metal 
341

342

343

344

345

346

347

348

349

350

351

352

353

354

355

356

357

358

359

360

361

362 363

contamination (Clements et al., 2000; Iwasaki, Schmidt \& Clements, 2018). These results

suggest that the metal contamination levels at sites $\mathrm{S} 1 \mathrm{a}$ and $\mathrm{S} 1 \mathrm{~b}$ might have been close to the threshold where some adverse effects on sensitive macroinvertebrates would be detected.

We observed several significantly lower values for some macroinvertebrate metrics at S2 compared with the corresponding reference site (R2), but few effects were observed at S2 in a previous study (Iwasaki et al., 2020b) or in the field sampling in September 2018 (Figures S1 and S2). The lower values at S2 could have been attributable to factors other than metal contamination, given that such lower values in the macroinvertebrate metrics were not often observed at the more upstream sites ( $\mathrm{S} 1 \mathrm{a}$ and $\mathrm{S} 1 \mathrm{~b})$. One possible factor is the presence of stenopsychid caddisflies (3.4 individuals per stone at R2; they were absent at S2). The biomass of macroinvertebrates can increase following colonization of the riverbed by net-spinning stream caddisfly larvae, which construct fixed "retreats" that increase riverbed stability and modify the microhabitat structure (Takao et al., 2006; Nunokawa et al., 2008; Statzner, 2012; Tumolo et al., 2019). These stenopsychid caddisfly larvae were collected at S2 and R2 (0.2 and 1.0 individuals per stone, respectively) in the field sampling in June 2017 (Iwasaki et al., 2020b) and collected at all the study sites including S2 and R2 in the field sampling in September 2018. Thus, we speculate that the differences in macroinvertebrate metrics between S2 and R2 might have been associated with the presence of stenopsychid caddisflies at R2. Also, given that these stenopsychid caddisflies were found at other metal-contaminated sites (Iwasaki et al., 2012) and that the net-spinning hydropsychid caddisflies show intermediate sensitivity to metals (Iwasaki, Schmidt \& Clements, 2018), the absence of stenopsychid caddisflies at S2 in this study could have resulted from factors other than metal contamination. While biological assessments like this study are useful for detecting ecological impairments in the field (Barbour et al., 1999), 
364 diagnostic tests for metal exposure and biomarkers may be valuable to further examine their 365 causes (Forbes, Palmqvist \& Bach, 2006; Miller et al., 2015).

366 With the exception of white-spotted char (S. leucomaenis), there were no effects of concern

367 for fish abundances or condition factors, even at the two most contaminated sites (S1a and S1b).

368 Although the abundance and condition factor of white-spotted char at S1a and S1b were

369 significantly lower than at the corresponding reference site, they were still within the reference

370 ranges. Given the relatively large variation and the limited number of individuals collected (a

371 total of 13), further study is likely required to reach a more firm conclusion for this species as

372 well as for lamprey (Lethenteron spp.). Results from fish sampling in September 2018 were

373 generally similar to our results (Figure S3), but there are inconsistencies; the contaminated sites

374 showing significant differences from reference sites varied between the two sampling periods.

375 However, these results at least suggest that there is little need for concern about the effects of

376 metal contamination on the abundance and condition factor of masu salmon, for which there is a

377 national hatchery at the mouth of the Tokushibetsu River. Our findings should provide valuable

378 information to those concerned about impacts of metal contamination on fishes in the studied

379 river (e.g., the local authority managing the closed mine, recreational anglers, and the fishery

380 agency running the hatchery program).

382 Conclusions

383 Overall, the results from our field study suggest that the richness and abundance of

384 macroinvertebrates (e.g., mayfly richness and abundance of heptageniid mayflies) are more

385 sensitive to metal contamination than the abundance and condition factor of fishes in the river

386 studied. Among macroinvertebrate community metrics, mayfly richness and abundance and 
387 heptageniid mayfly abundance have been identified as sensitive (Carlisle \& Clements, 1999;

388 Clements et al., 2000; Iwasaki, Schmidt \& Clements, 2018). Also, these differences in responses

389 to metal contamination have been reported in several studies, and metrics based on fishes are

390 generally less responsive to metal contamination than those based on macroinvertebrates

391 (Freund \& Petty, 2007; Clements, Vieira \& Church, 2010; Namba et al., 2020), which is

392 consistent with our results. Although it is difficult to determine the underlying reasons for these

393 differences, spatial-temporal characteristics of organisms' responses to metal contamination

394 should have an important role; macroinvertebrates tend to reflect local and more recent

395 conditions than fishes, which are more mobile and relatively longer-lived. Compared with

macroinvertebrates, however, the number of fishes captured and the associated metrics were

limited in our study. For instance, benthic fishes such as sculpins can be more responsive to

metals than salmonids (Munkittrick \& Dixon, 1989b; Maret \& MacCoy, 2002), and physiological

and biochemical responses of fishes have been employed as early warnings for the population

level effects (Forbes, Palmqvist \& Bach, 2006; Hanson, 2009). It would therefore be valuable to

accumulate empirical evidence for ecological indicators sensitive to metal contamination within

and among biological groups to choose which groups to survey for general environmental impact assessments in contaminated rivers.

404

\section{Acknowledgements}

This paper does not necessarily reflect the policies or views of any government agencies. We are grateful to Susumu Norota, Tatsushi Miyazaki, and Kazutoshi Ueda for their kind help to conduct the field sampling, and Kaori Nakahata for help with the fish measurements in the laboratory. 


\section{References}

412 Adams W, Blust R, Dwyer R, Mount D, Nordheim E, Rodriguez PH, and Spry D. 2020.

413 Bioavailability assessment of metals in freshwater environments: A historical review. 414 Environmental Toxicology and Chemistry 39:48-59. 10.1002/etc.4558

415 Barbour MT, Gerritsen J, Snyder BD, and Stribling JB. 1999. Rapid bioassessment protocols for 416 use in streams and wadeable rivers: periphyton, benthic macroinvertebrates and fish (second communities in Colorado mountain streams. Ecological Applications 10:626-638. 
433 Clements WH, Vieira NKM, and Church SE. 2010. Quantifying restoration success and recovery 434 in a metal-polluted stream: a 17-year assessment of physicochemical and biological responses. Journal of Applied Ecology 47:899-910.

436

de Morais GF, dos Santos Ribas LG, Ortega JCG, Heino J, and Bini LM. 2018. Biological surrogates: A word of caution. Ecological Indicators 88:214-218. 10.1016/j.ecolind.2018.01.027

Environment and Climate Change Canada. 2015. Third national assessment of environmental effects monitoring data from metal mines. Gatineau, QC, Canada.

Forbes VE, Palmqvist A, and Bach L. 2006. The use and misuse of biomarkers in ecotoxicology. Environmental Toxicology and Chemistry 25:272-280.

Freund JG, and Petty JT. 2007. Response of fish and macroinvertebrate bioassessment indices to water chemistry in a mined Appalachian watershed. Environmental Management 39:707720. $10.1007 / \mathrm{s} 00267-005-0116-3$

Geological Survey of Japan. 2015. Seamless digital geological map of Japan 1: 200,000. May 29, 2015 version. Geological Survey of Japan, National Institute of Advanced Industrial Science and Technology.

Hanson N. 2009. Population level effects of reduced fecundity in the fish species perch (Perca fluviatilis) and the implications for environmental monitoring. Ecological Modelling 220:2051-2059.

Heino J. 2010. Are indicator groups and cross-taxon congruence useful for predicting biodiversity in aquatic ecosystems? Ecological Indicators 10:112-117. 10.1016/j.ecolind.2009.04.013 
454 Hickey CW, and Clements WH. 1998. Effects of heavy metals on benthic macroinvertebrate

455

456

457

458

459

460

461

462

463

464

465

466

467

468

469

470

471

472

473

474

475

476

communities in New Zealand streams. Environmental Toxicology and Chemistry 17:23382346.

Hokkaido Prefecture. 2018. Report on work, survey, and analysis for preventing abandoned mine pollution in the fiscal year of 2017.

Iwasaki N, Inao K, Ueda K, and (CD-ROM). 2020a. Development of tool and database for estimating river basin land use. Proceedings of 29th academic research presentation meeting of GIS Association of Japan (CD-ROM), available from https://githubcom/q-japanese-riverbasin/QJRB/.

Iwasaki Y, Fujisawa M, Ogino T, Mano H, Shinohara N, Masunaga S, and Kamo M. 2020b. Does a sum of toxic units exceeding 1 imply adverse impacts on macroinvertebrate assemblages? A field study in a northern Japanese river receiving treated mine discharge. Environmental Monitoring and Assessment 192:83. 10.1007/s10661-019-8047-2

Iwasaki Y, Kagaya T, Miyamoto K, and Matsuda H. 2012. Responses of riverine macroinvertebrates to zinc in natural streams: implications for the Japanese water quality standard. Water, Air, and Soil Pollution 223:145-158.

Iwasaki Y, and Ormerod SJ. 2012. Estimating safe concentrations of trace metals from intercontinental field data on river macroinvertebrates. Environmental Pollution 166:182-186.

Iwasaki Y, Schmidt TS, and Clements WH. 2018. Quantifying differences in responses of aquatic insects to trace metal exposure in field studies and short-term stream mesocosm experiments. Environmental Science \& Technology 52:4378-4384. 10.1021/acs.est.7b06628

Kimball KD, and Levin SA. 1985. Limitations of laboratory bioassays: The need for ecosystemlevel testing. Bioscience 35:165-171. 
477 Maret TR, and MacCoy DE. 2002. Fish assemblages and environmental variables associated with 478 hard-rock mining in the Coeur d'Alene river basin, Idaho. Transactions of the American Fisheries Society 131:865-884. 10.1577/1548-8659(2002)131<0865:Faaeva>2.0.Co;2

Miller LL, Isaacs MA, Martyniuk CJ, and Munkittrick KR. 2015. Using molecular biomarkers and traditional morphometric measurements to assess the health of slimy sculpin (Cottus cognatus) from streams with elevated selenium in North-Eastern British Columbia. Environmental Toxicology and Chemistry 34:2335-2346. 10.1002/etc.3064

Miyakoshi Y, Sasaki Y, Fujiwara M, Tanaka K, Matsueda N, Irvine JR, and Kitada S. 2009. Implications of recreational fishing on juvenile masu salmon stocked in a Hokkaido river. North American Journal of Fisheries Management 29:33-39. 10.1577/M08-107.1

Morita K, Sahashi G, and Tsuboi J-i. 2016. Altitudinal niche partitioning between white-spotted charr (Salvelinus leucomaenis) and masu salmon (Oncorhynchus masou) in a Japanese river. Hydrobiologia 783:93-103. 10.1007/s10750-015-2571-z

Munkittrick KR, and Dixon DG. 1989a. A holistic approach to ecosystem health assessment using fish population characteristics. Hydrobiologia 188:123-135. 10.1007/BF00027777

Munkittrick KR, and Dixon DG. 1989b. Use of white sucker (Catostomus commersoni) populations to assess the health of aquatic ecosystems exposed to low-level contaminant stress. Canadian Journal of Fisheries and Aquatic Sciences 46:1455-1462. 10.1139/f89-185

Namba H, Iwasaki Y, Heino J, and Matsuda H. 2020. What to survey? A systematic review of the choice of biological groups in assessing ecological impacts of metals in running waters. Environmental Toxicology and Chemistry 39:1964-1972. 10.1002/etc.4810 
498 Niederlehner BR, Pontasch KW, Pratt JR, and Cairns J. 1990. Field evaluation of predictions of 499 environmental effects from a multispecies-microcosm toxicity test. Archives of Environmental Contamination and Toxicology 19:62-71.

501 Nriagu JO, and Pacyna JM. 1988. Quantitative assessment of worldwide contamination of air, water and soils by trace-metals. Nature 333:134-139.

Nunokawa M, Gomi T, Negishi JN, and Nakahara O. 2008. A new method to measure substrate coherent strength of Stenopsyche marmorata. Landscape and Ecological Engineering 4:125-131. 10.1007/s11355-008-0044-5

R Core Team. 2019. R: A language and environment for statistical computing. Vienna, Austria: R Foundation for Statistical Computing.

Statzner B. 2012. Geomorphological implications of engineering bed sediments by lotic animals. Geomorphology 157-158:49-65. 10.1016/j.geomorph.2011.03.022

Takao A, Negishi JN, Nunokawa M, Gomi T, and Nakahara O. 2006. Potential influences of a netspinning caddisfly (Trichoptera: Stenopsyche marmorata) on stream substratum stability in heterogeneous field environments. Journal of the North American Benthological Society 25:545-555.

Takayasu M, Eguchi H, Kimura G, and Hayasaka S. 1964. Research on the death of salmon in the Tokushibetsu River (1). Scientific reports of the Hokkaido Salmon Hatchery:27-39.

Tokeshi M. 2009. Species Coexistence: Ecological and Evolutionary Perspectives. Oxford, UK: Blackwell Science.

Tumolo BB, Albertson LK, Cross WF, Daniels MD, and Sklar LS. 2019. Occupied and abandoned structures from ecosystem engineering differentially facilitate stream community colonization. Ecosphere 10:e02734. 10.1002/ecs2.2734 
521 [U.S. EPA] U.S. Environmental Protection Agency. 1994. Method 200.8: Determination of Trace

522 Elements in Waters and Wastes by Inductively Coupled Plasma-Mass Spectrometry, 523 Revison 5.4. Cincinnati, OH.

524 [U.S. EPA] U.S. Environmental Protection Agency. 2002. National Recommended Water Quality 525 Criteria: EPA822-R-02-047. Washington, DC.

526 [U.S. EPA] U.S. Environmental Protection Agency. 2007. Aquatic Life Ambient Freshwater 527 Quality Criteria - Copper 2007 Revision, EPA-822-F-07-001. Washington, DC.

528 Volk EC, Schroder SL, and Grimm JJ. 1999. Otolith thermal marking. Fisheries Research 43:205529 219. $10.1016 / \mathrm{S} 0165-7836(99) 00073-9$ 
Figure 1

Map showing location of the study area and sampling sites.

Map was created using Quantum Geographic Information System (QGIS version 3.10;

http://agis.osgeo.org) based on National Land Numerical Information provided by Geospatial Information Authority of Japan (http://nlftp.mlit.go.jp/ksj/).

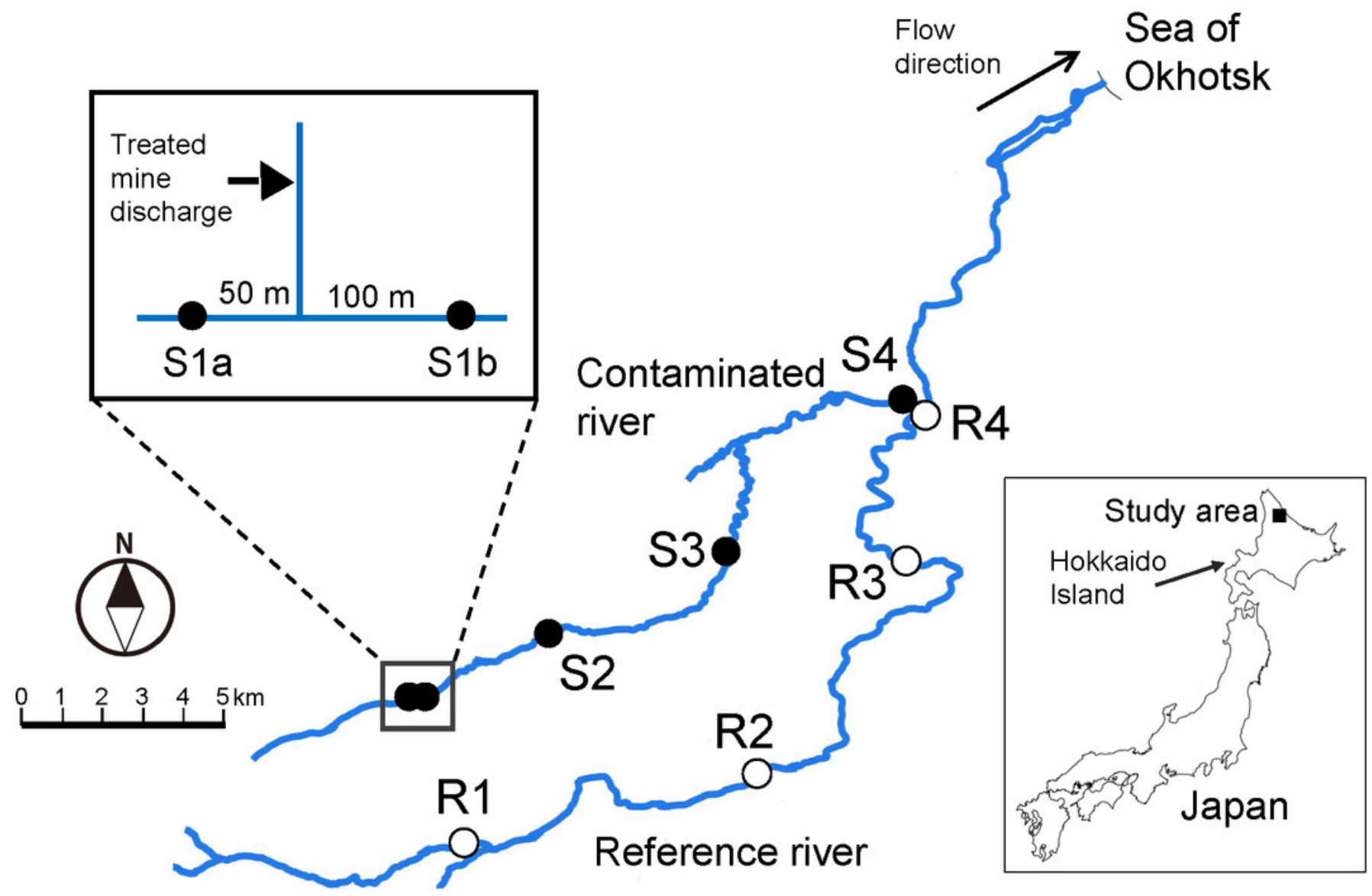


Figure 2

Taxon richness (number of taxa; $A-D$ ) and abundance (number of individuals; $E-H$ ) of macroinvertebrates at reference (R1-R4) and contaminated (S1a-S4) sites.

The same symbols indicate sites with similar elevations. Error bars indicate $90 \%$ confidence intervals of site means. Horizontal lines and gray areas are the means and $90 \%$ confidence intervals calculated from means for the four reference sites, respectively. Asterisks indicate contaminated sites with values significantly lower or higher than the corresponding reference sites with similar elevation $(P<0.05)$.
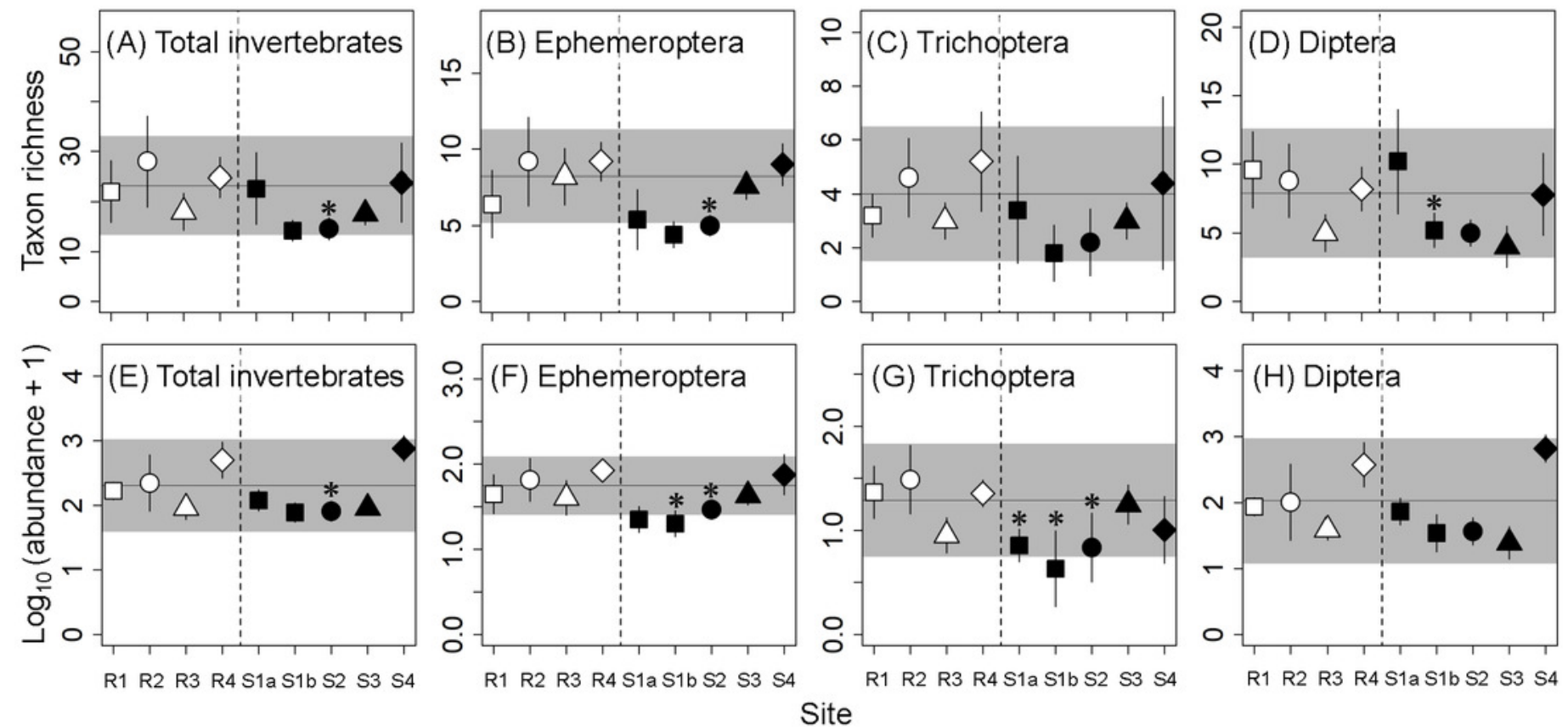
Figure 3

Abundance (number of individuals per stone) of dominant families (A-F) of macroinvertebrates at reference (R1-R4) and contaminated (S1a-S4) sites.

The same symbols indicate sites with similar elevations. Error bars indicate $90 \%$ confidence intervals of site means. Horizontal lines and gray areas are the means and $90 \%$ confidence intervals calculated from means for the four reference sites, respectively. Asterisks indicate contaminated sites with values significantly lower or higher than the corresponding reference sites with similar elevations $(P<0.05)$.

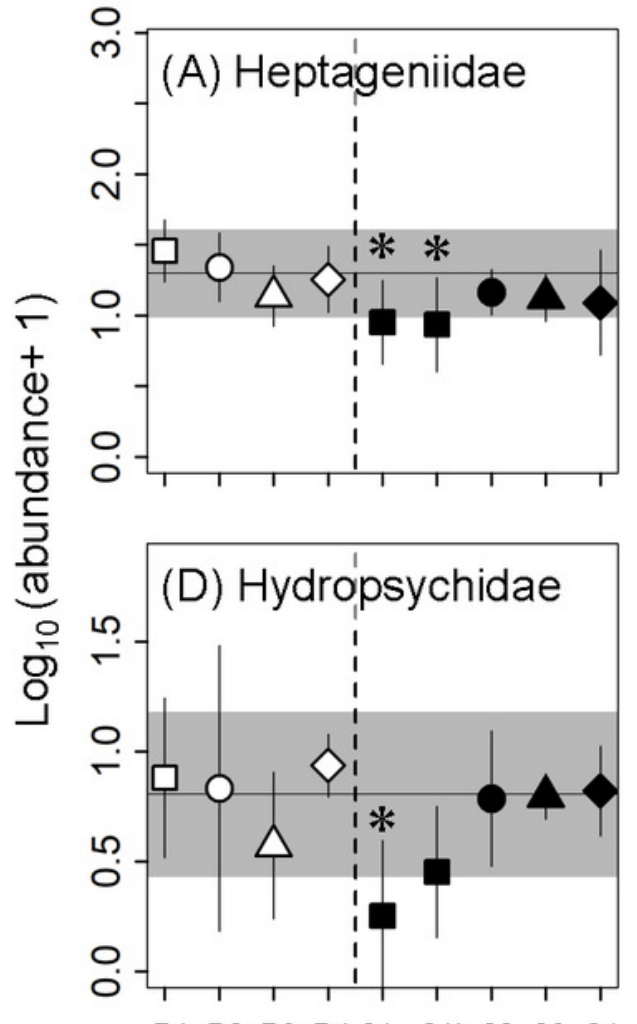

R1 R2 R3 R4 S1a S1b S2 S3 S4
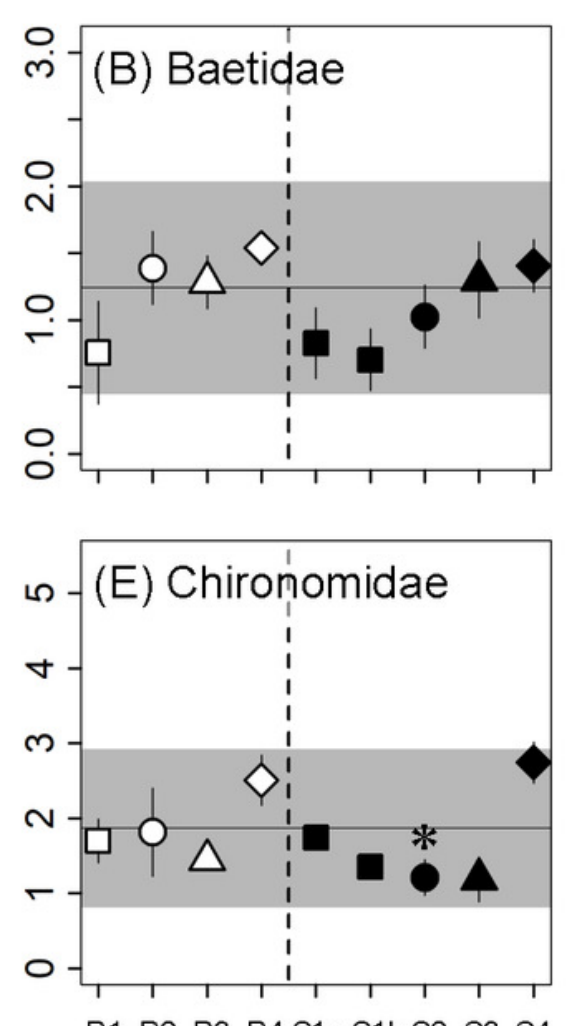

R1 R2 R3 R4 S1a S1b S2 S3 S4

Site
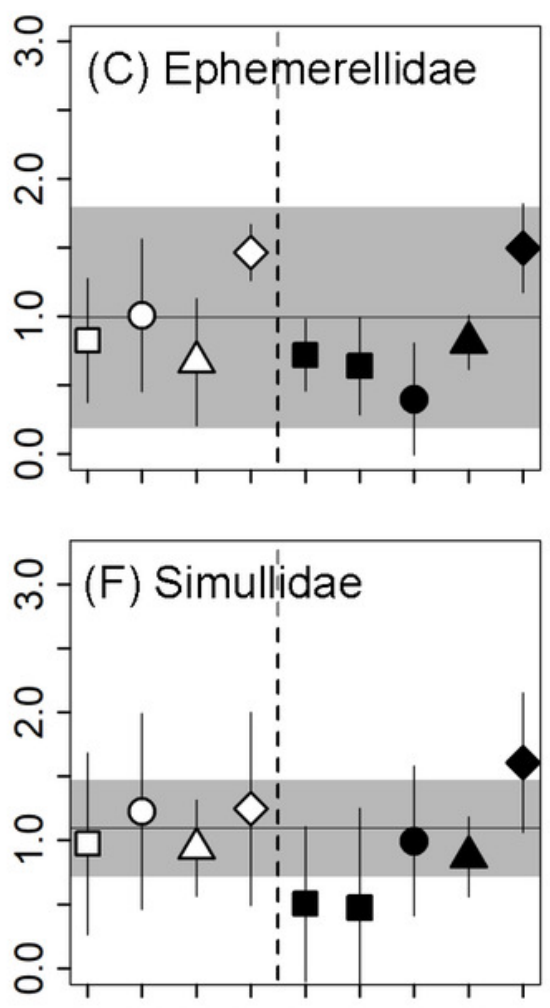

R1 R2 R3 R4 S1a S1b S2 S3 S4 


\section{Figure 4}

Abundance (number of individuals per $\left.50 \mathrm{~m}^{2} ; A-D\right)$ and condition factor $(E-H)$ of fishes at reference (R1-R4) and contaminated (S1a-S4) sites.

The same symbols indicate sites with similar elevations. Error bars indicate $90 \%$ confidence intervals of site means. Horizontal lines and gray areas are the means and $90 \%$ confidence intervals calculated from means for the four reference sites, respectively. Asterisks indicate contaminated sites with values significantly lower or higher than the corresponding reference sites with similar elevations $(P<0.05)$. For $S$. leucomaenis, the $90 \%$ confidence interval was not calculated from reference site means because this species was only captured at one reference site (R1).
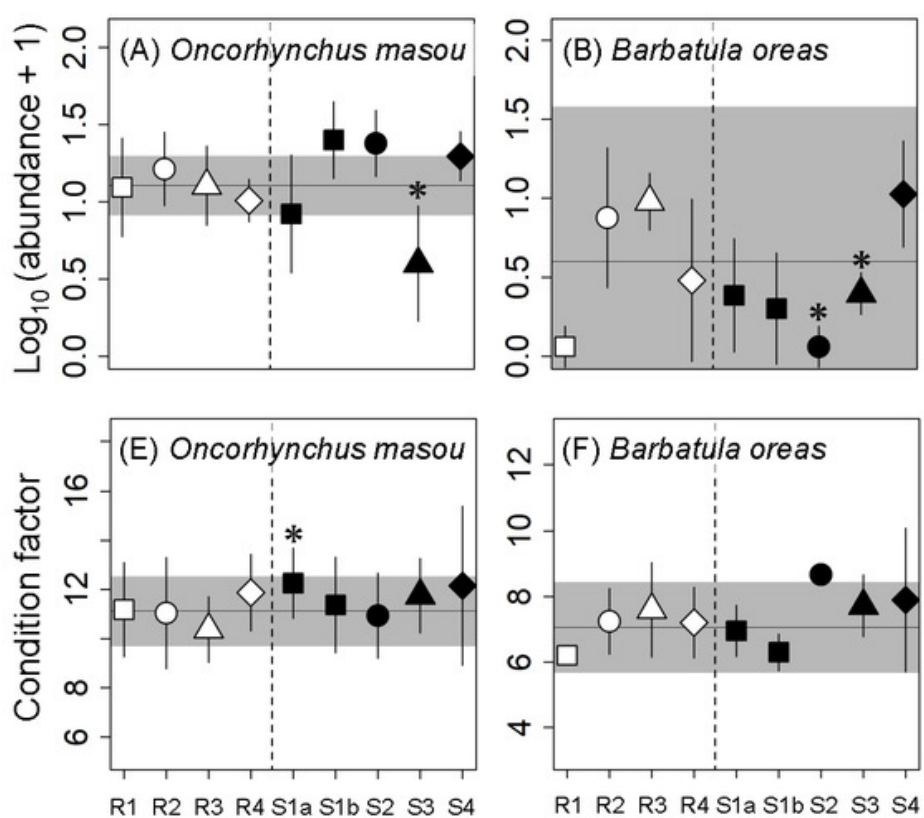

Site
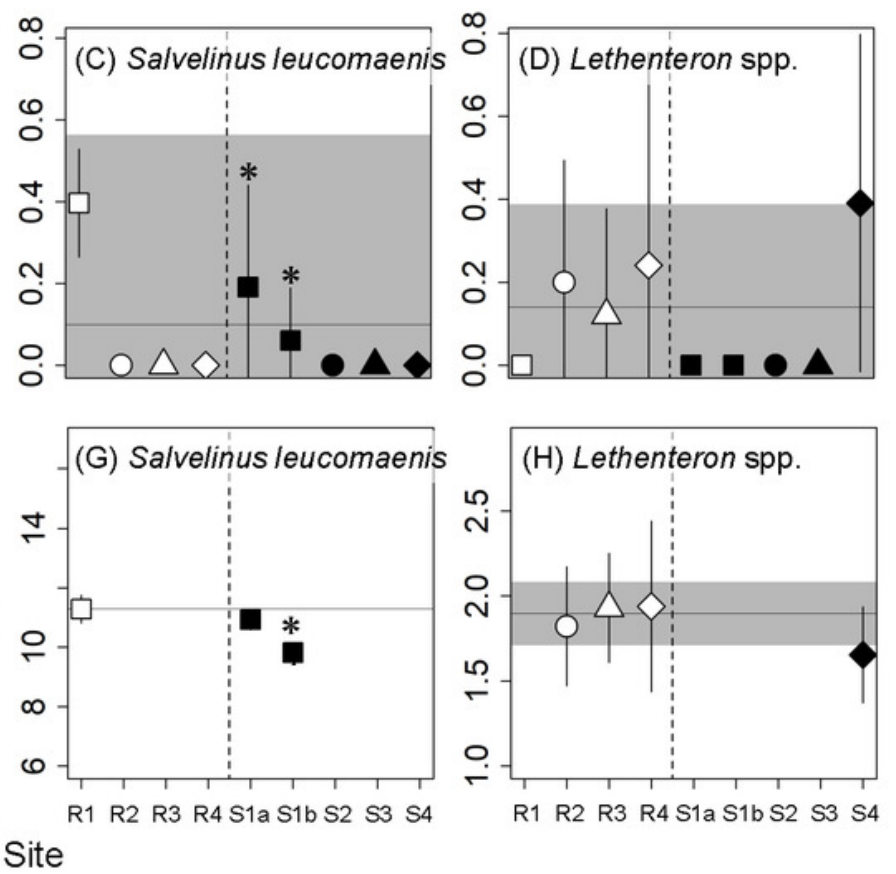


\section{Table 1 (on next page)}

Physical parameters at the study sites in the Tokushibetsu River system, northern Japan

Depth, velocity, and relative surface area for sampled stones are the means (and standard deviations) of five stones sampled. 
1 Table 1. Physical parameters at the study sites in the Tokushibetsu River system, northern Japan

\begin{tabular}{|c|c|c|c|c|c|c|c|c|c|}
\hline \multirow[b]{2}{*}{ Site } & \multirow[b]{2}{*}{$\begin{array}{c}\text { Elevation } \\
\text { (m a.s.1.) }\end{array}$} & \multirow[b]{2}{*}{$\begin{array}{c}\text { Catchment } \\
\text { area } \\
\left(\mathrm{km}^{2}\right)\end{array}$} & \multirow[b]{2}{*}{$\begin{array}{l}\text { Channel } \\
\text { width } \\
\text { (m) }\end{array}$} & \multicolumn{3}{|c|}{ Studied riffles } & \multicolumn{3}{|c|}{ Sampled stones } \\
\hline & & & & $\begin{array}{l}\text { Width } \\
\text { (m) }\end{array}$ & $\begin{array}{c}\text { Maximum } \\
\text { depth } \\
(\mathrm{cm})\end{array}$ & $\begin{array}{c}\text { Maximum } \\
\text { velocity } \\
(\mathrm{cm} / \mathrm{s})\end{array}$ & $\begin{array}{l}\text { Depth } \\
(\mathrm{cm})\end{array}$ & $\begin{array}{c}\text { Velocity } \\
(\mathrm{cm} / \mathrm{s})\end{array}$ & $\begin{array}{c}\text { Relative } \\
\text { surface area } \\
\left(\mathrm{cm}^{2}\right)\end{array}$ \\
\hline \multicolumn{10}{|c|}{ Contaminated sites } \\
\hline S1a & 330 & 18 & 11 & 4.5 & 27 & 170 & $6.9(3.5)$ & $102(33)$ & $1026(403)$ \\
\hline $\mathrm{S} 1 \mathrm{~b}$ & 330 & 19 & 10 & 8.6 & 28 & 170 & $6.3(3.2)$ & $73(27)$ & $851(169)$ \\
\hline $\mathrm{S} 2$ & 230 & 29 & 9 & 9 & 25 & 165 & $7.6(3.6)$ & $98(25)$ & $1003(260)$ \\
\hline S3 & 130 & 46 & 11 & 14 & 25 & 200 & $6.6(2.5)$ & $98(31)$ & $1192(404)$ \\
\hline S4 & 30 & 117 & 21 & 5.1 & 25 & 230 & $6.5(2.8)$ & $89(24)$ & $1114(396)$ \\
\hline \multicolumn{10}{|c|}{ Reference sites } \\
\hline $\mathrm{R} 1$ & 285 & 27 & 11 & 11 & 26 & 180 & $7.4(1.2)$ & $87(47)$ & $1016(278)$ \\
\hline $\mathrm{R} 2$ & 170 & 77 & 14 & 11 & 25 & 170 & $4.2(1.6)$ & $91(40)$ & $931(311)$ \\
\hline $\mathrm{R} 3$ & 75 & 107 & 21 & 16 & 23 & 170 & $6.4(3.3)$ & $100(36)$ & $1007(280)$ \\
\hline R4 & 35 & 127 & 24 & 7.7 & 24 & 170 & $5.5(1.7)$ & $86(24)$ & $1039(322)$ \\
\hline
\end{tabular}

2 Depth, velocity, and relative surface area for sampled stones are the means (and standard deviations) of five stones sampled. 


\section{Table 2 (on next page)}

Water-quality measurements at study sites in the Tokushibetsu River system, northern Japan (26-28 June 2018)

DO, dissolved oxygen; DOC, dissolved organic carbon; CCU, cumulative criterion unit (see text for details); Temp, temperature; WQC, U.S. EPA chronic water-quality criterion at a water hardness of $10 \mathrm{mg} / \mathrm{L}$ (U.S. EPA 2002). Limits of quantification for $\mathrm{Cu}, \mathrm{Zn}, \mathrm{Cd}$, and Pb were $0.001,0.06,0.005$, and $0.005 \mu \mathrm{g} / \mathrm{L}$, respectively. 
1 Table 2. Water-quality measurements at study sites in the Tokushibetsu River system, northern Japan (26-28 June 2018)

\begin{tabular}{|c|c|c|c|c|c|c|c|c|c|c|c|}
\hline Site & $\mathrm{Cu}$ & $\begin{array}{c}\mathrm{Cd} \\
\text { Dissolve }\end{array}$ & $\begin{array}{c}\mathrm{Pb} \\
\mathrm{d}(\mu \mathrm{g} / \mathrm{L})\end{array}$ & $\mathrm{Zn}$ & $\begin{array}{c}\mathrm{CCU} \\
\square\end{array}$ & $\begin{array}{l}\text { Temp } \\
\left({ }^{\circ} \mathrm{C}\right)\end{array}$ & $\begin{array}{r}\mathrm{pH} \\
\square\end{array}$ & $\begin{array}{c}\mathrm{DO} \\
(\mathrm{mg} / \mathrm{L})\end{array}$ & $\begin{array}{c}\text { DOC } \\
(\mathrm{mg} / \mathrm{L})\end{array}$ & $\begin{array}{c}\text { Conductivity } \\
(\mu \mathrm{s} / \mathrm{cm})\end{array}$ & $\begin{array}{c}\text { Hardness } \\
(\mathrm{mg} / \mathrm{L})\end{array}$ \\
\hline \multicolumn{12}{|c|}{ Contaminated sites } \\
\hline S1a & 1.0 & 0.13 & 0.69 & 24.0 & 8.4 & 9.1 & 7.1 & 11 & 0.3 & 54 & 13 \\
\hline $\mathrm{S} 1 \mathrm{~b}$ & 1.1 & 0.16 & 0.71 & 27.5 & 9.4 & 9.3 & 7.0 & 11 & 0.4 & 52 & 13 \\
\hline $\mathrm{S} 2$ & 0.8 & 0.17 & 0.25 & 25.9 & 6.8 & 9.4 & 7.2 & 11 & 0.3 & 57 & 14 \\
\hline S3 & 0.5 & 0.07 & 0.23 & 11.5 & 3.8 & 11.5 & 7.4 & 11 & 0.4 & 56 & 13 \\
\hline S4 & 0.3 & $<0.005$ & 0.05 & 4.8 & 0.9 & 10.2 & 7.5 & 11 & 0.7 & 60 & 14 \\
\hline \multicolumn{12}{|c|}{ Reference sites } \\
\hline $\mathrm{R} 1$ & 0.1 & $<0.005$ & 0.09 & 25.3 & 2.1 & 10.6 & 7.5 & 10 & 0.8 & 41 & 10 \\
\hline $\mathrm{R} 2$ & 0.1 & $<0.005$ & $<0.005$ & 0.1 & 0.1 & 10.2 & 7.5 & 11 & 0.7 & 46 & 11 \\
\hline R3 & 0.1 & $<0.005$ & 0.04 & 0.1 & 0.3 & 11.7 & 7.7 & 11 & 0.6 & 48 & 11 \\
\hline $\mathrm{R} 4$ & 0.1 & $<0.005$ & 0.03 & 0.3 & 0.3 & 9.7 & 8.0 & 12 & 0.7 & 50 & 12 \\
\hline WQC & 1.3 & 0.05 & 0.19 & 16.8 & $\square$ & $\square$ & $\square$ & $\square$ & $\square$ & $\square$ & $\square$ \\
\hline
\end{tabular}

2 DO, dissolved oxygen; DOC, dissolved organic carbon; CCU, cumulative criterion unit (see text for details); Temp, temperature;

3 WQC, U.S. EPA chronic water-quality criterion at a water hardness of $10 \mathrm{mg} / \mathrm{L}$ (U.S. EPA 2002). Limits of quantification for Cu, Zn,

$4 \mathrm{Cd}$, and $\mathrm{Pb}$ were $0.001,0.06,0.005$, and $0.005 \mu \mathrm{g} / \mathrm{L}$, respectively. 